\title{
Assessment of medical journal quality
}

\author{
Richard N Fedorak MD FRCPC \\ President, Canadian Association of Gastroenterology
}

E valuating the quality of a journal is a difficult task because quality means many different things to many different people. Nevertheless, the quality or rank of a medical journal is becoming increasingly important in determining the promotion of academic faculty, the quality of manuscripts submitted for consideration for publication, the quality of reviewers and reviews, the readership and number of subscribers, and the opportunity for advertising revenue. Taken together, these items often determine the life or death of a medical journal.

Objective measurements of a journal's quality have recently been devised; an immediacy index and an impact factor are calculated by using the number of total citations for the articles published in a particular journal.

\section{DEFINITIONS}

Citation: The formal acknowledgment of intellectual debt to previously published research that is publicly recorded in the reference section of a contemporary publication.

Total citations: The total number of times that each journal has been cited by all journals within the current product year.

Article count: The number of articles published in a journal in a particular year or years. Editorials, letters, news items and meeting abstracts are not included in article counts because they are not generally cited.

Impact factor: The journal's impact factor is a measure of the frequency with which the 'average article' in a journal has been cited in a particular year. The impact factor helps in the evaluation of a journal's relative importance, especially when it is compared with others in the same field. Within the field of gastroenterology and hepatology there are 44 journals ranked with an impact factor. The highest impact factor is 10.330 and the lowest is 0.061 . The Canadian Journal of Gastroenterology ranks a respectable 30th in this category.

The impact factor is calculated by dividing the number of current citations of articles published in the two previous years by the total number of articles published in the two previous years.

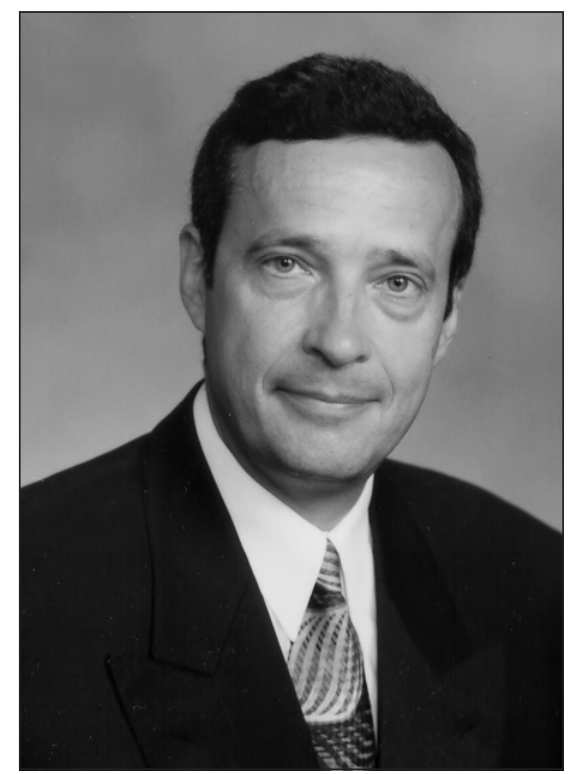

The impact factor calculation for the Canadian Journal of Gastroenterology is as follows:

Number of articles published in 1997 cited in 1998: 53
Number of articles published in 1996 cited in 1998: 17
Total: 70
Number of articles published in 1997: 77
Number of articles published in 1996: 59
Total: 136
Impact factor $=\frac{\text { Citations of } 1996 \text { and } 1997 \text { articles }}{\text { Number of articles published in } 1996 \text { and } 1997}$
$=\frac{70}{136}$
$=0.515$

Immediacy index: The journal's immediacy index is a measure of how quickly the 'average article' in a journal is cited. The immediacy index is an indication of how often articles published in a journal are cited within the same year. Within the field of gasotroenterology and hepatology there are 44 
journals ranked with an immediacy index. The highest immediacy index is 2.324 and the lowest is zero. The Canadian Journal of Gastroenterology ranks an excellent ninth in this category.

The immediacy index is calculated by dividing the number of citations of articles published in a given year by the number of articles published in that year.

The immediacy index for the Canadian Journal of Gastroenterology is as follows:

Number of articles published in 1998 and cited in 1998: 16

Number of articles published in 1998: 56

Immediacy index $=\frac{\text { Citations of } 1998 \text { articles }}{\text { Number of } 1998 \text { articles }}$

$=\frac{16}{56}$

$=0.286$

\section{POTENTIAL PITFALLS}

Citations: Citation counts are determined from a citation database drawn from over 8400 scholarly and technical journals worldwide. Coverage is both multidisciplinary and international, and incorporates journals from over 3000 publishers in 60 nations and includes virtually all specialties in the areas of science, technology and social science.

Citation data are not meant to replace informed peer review. Additionally, careful attention should be paid to the many conditions that can influence citation rates, such as language, journal history and format, publication schedule and subject specialty, all of which can influence their citation patterns. This information should be taken into account in any comparative journal citation analysis.

Impact factor: The following conditions may affect a journal's ranking and impact factor.
Impact factor determined by article type: Citation counts do not distinguish among citations of letters, reviews or original research articles. Article counts include only original research and review articles. If a journal publishes a large number of letters, there may be a temporary increase in the number of citations received.

Changes in journal format: Sudden changes in a journal's size can affect the impact factor. The average number of citations per article (ie, impact factor) is lowered when there are more one-year-old articles than two-year-old articles because article citation rates tend to peak in the second year after publication. Likewise, when an article count drops, the impact factor may rise temporarily.

Title changes: In the first year after a title change, the new title is listed without an impact factor because the article count for the two preceding years is zero. The superseded title is listed with a normal impact factor. One year later, separate impact factors for the new title and for the superseded title are listed. In this second year, the impact factor for a new title may be lower than expected because the article count includes only newer articles. Similarly, the impact factor for the superseded title may be higher than expected because it is based only on older articles.

Immediacy index: Because the immediacy index is an average per article, it tends to discount the advantage of large journals over small ones. However, frequently issued journals may have an advantage because an article published early in the year has a better chance of being cited than one published later in the year. When comparing journals that specialize in cutting edge research, the immediacy index can provide a useful perspective on the 'hottest' journal. 


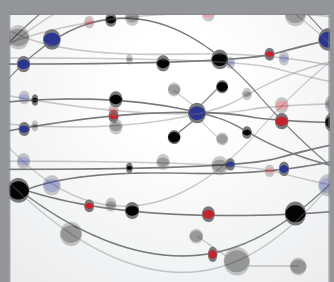

The Scientific World Journal
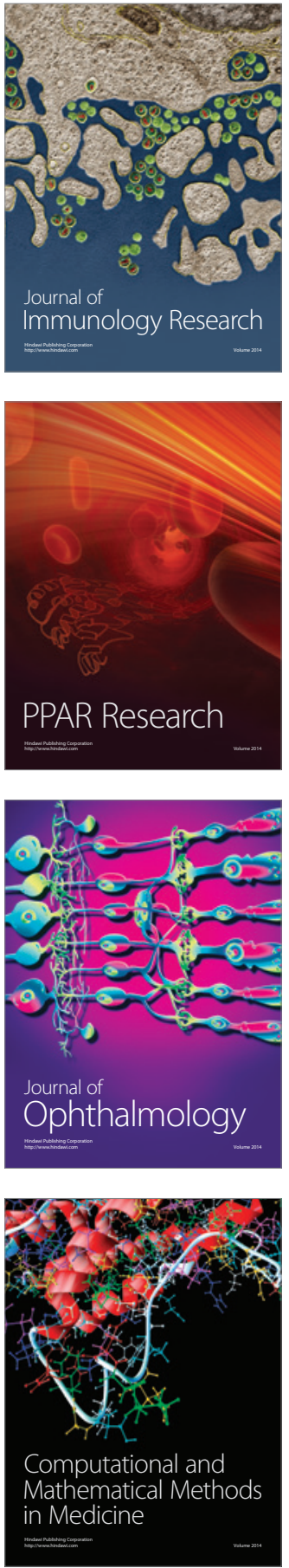

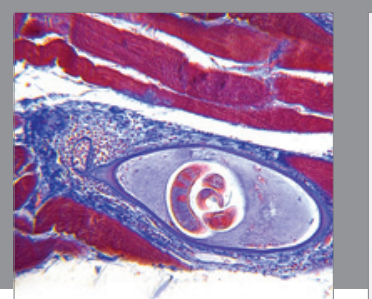

Gastroenterology Research and Practice

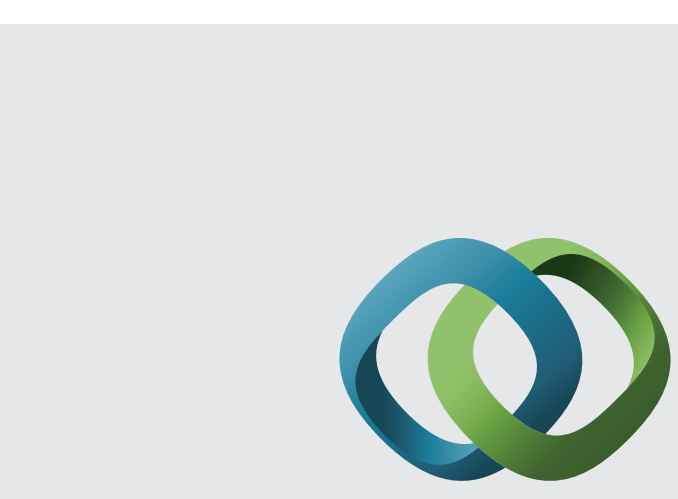

\section{Hindawi}

Submit your manuscripts at

http://www.hindawi.com
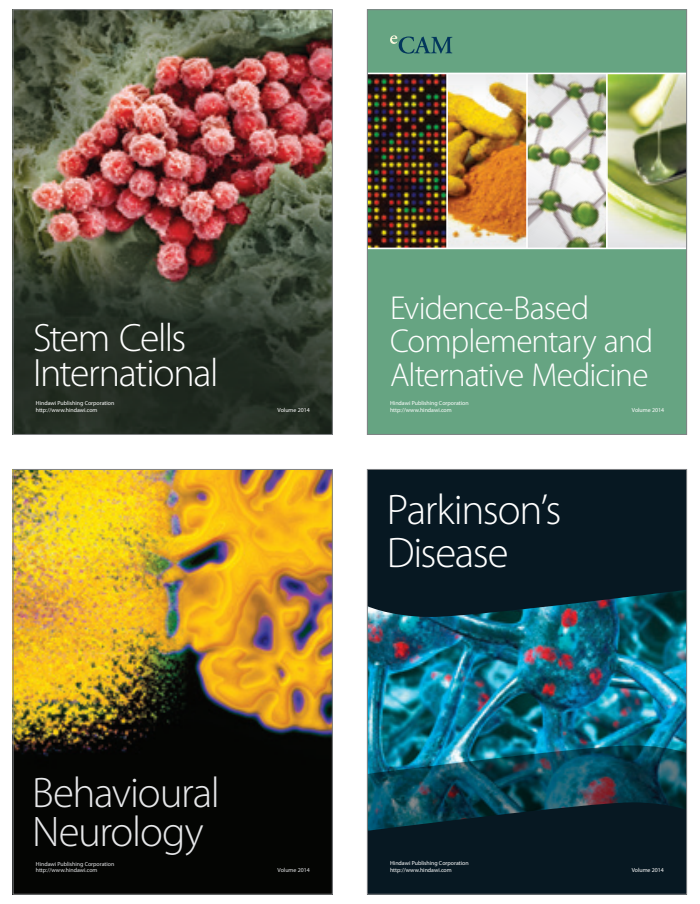
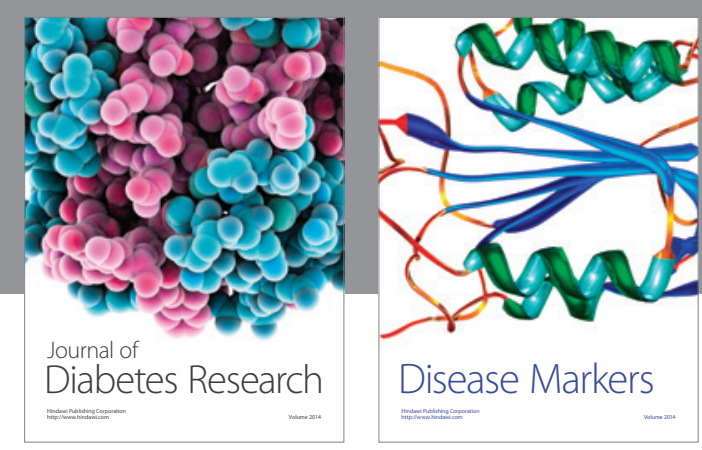

Disease Markers
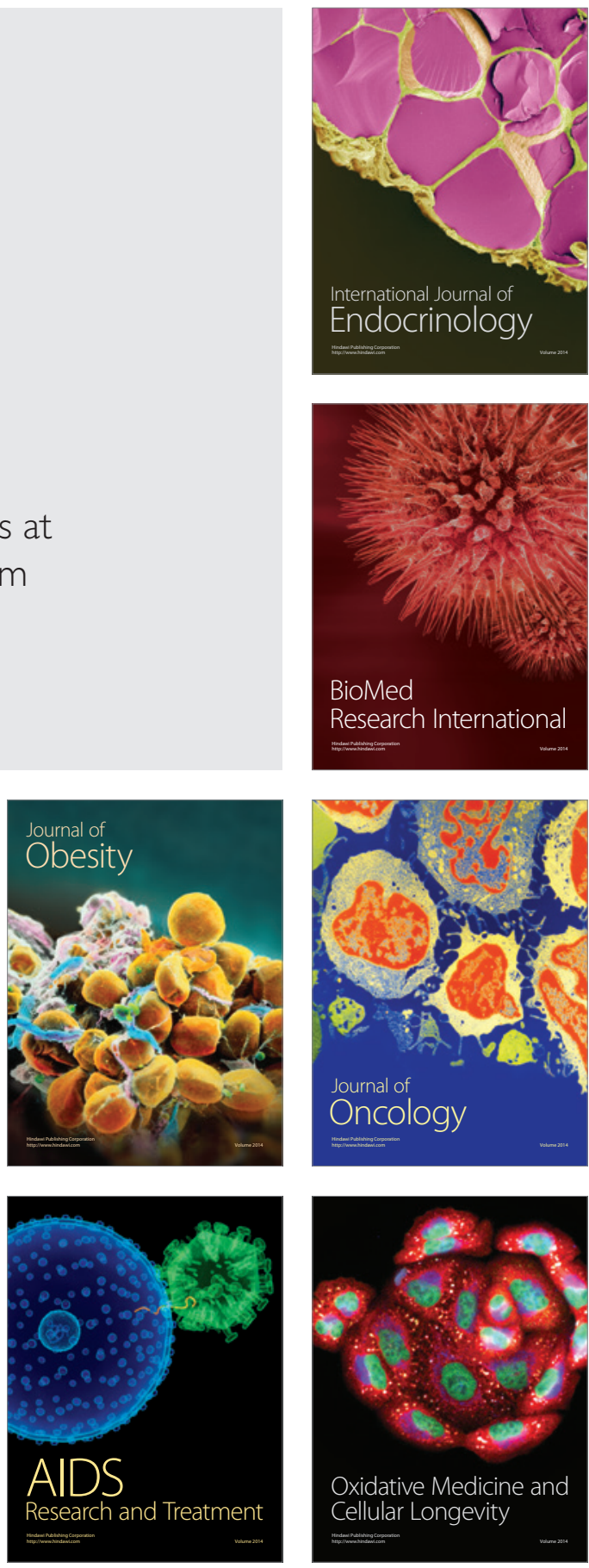